\title{
ANALISIS KEPUASAN PENUMPANG GERBONG KERETA API KHUSUS WANITA MENGGUNAKAN MODEL SERVQUAL
}

\author{
Wing Ispurwanto; Vany Widya Pricillia \\ Jurusan Psikologi, Fakultas Psikologi, Bina Nusantara University \\ Jln. Kemanggisan Ilir III No. 45, Kemanggisan, Palmerah, Jakarta Barat 11480
}

\begin{abstract}
ABSTRAK
To find women's representation of passenger satisfaction for the special woman carriage train service traveling the routes of Bogor to Jakarta, researcher performed a descriptive quantitative research with a population of rail passengers. Data taken from 80 respondents using incidental sampling technique is analyzed using the SERVQUAL model. Research results show that overall passenger satisfaction levels of service specific car is at the level of discontent. This can be seen from the gap between perceptions and negative expectations. Dimensions of service quality perceived by passengers are not satisfied that the dimensions of connection, reliability, response and physical evidence. However there are several dimensions of service quality perceived by passengers quite happy. Dimensions are empathy, facilities, security and comfort. This research concludes that there is a perception gap between the expectations of the ministry with a value of -1.101. Therefore, it is recommended to train the managers to improve service for passengers, especially the dimensions of felt unsatisfactory by passengers.
\end{abstract}

Keywords: passenger satisfaction, ladies only carriage, servqual model

\begin{abstract}
ABSTRAK
Untuk mengetahui gambaran kepuasan penumpang wanita terhadap adanya pelayanan kereta api gerbong khusus wanita rute perjalanan Bogor-Jakarta (PP) dilakukan penelitian kuantitatif deskriptif dengan populasi penumpang kereta api. Data diambil dengan angket atau kuesioner sebanyak 80 responden menggunakan teknik incidental sampling sedangkan analisis data yang digunakan model SERVQUAL. Hasil penelitian menunjukkan bahwa secara keseluruhan tingkat kepuasan penumpang terhadap pelayanan gerbong khusus wanita berada pada level tidak puas. Hal ini terlihat dari nilai kesenjangan antara persepsi dan harapan yang negatif. Dimensi kualitas pelayanan yang dirasakan tidak puas oleh penumpang yakni dimensi koneksi,reliabilitas,daya tanggap dan bukti fisik. Walaupun demikian ada juga beberapa dimensi kualitas pelayanan yang dirasakan cukup puas oleh penumpang. Dimensi tersebut adalah empati, kemudahan, jaminan dan kenyamanan Dari penelitian ini diperoleh hasil yakni adanya kesenjangan antara harapan dengan persepsi pelayanan dengan nilai sebesar -1,101. Oleh karena itu, disarankan kepada pihak pengelola kereta api untuk meningkatkan pelayanan terhadap penumpang khususnya dimensi pelayanan yang dirasa tidak memuaskan bagi penumpang.
\end{abstract}

Kata kunci: kepuasan penumpang, gerbong khusus wanita, model servqual 


\section{PENDAHULUAN}

Moda transportasi ini paling diminati oleh masyarakat. Sebanyak 577.262 orang atau sebesar 2,8 persen masyarakat khususnya di wilayah Jakarta dan sekitarnya menggunakan kereta api setiap hari (Dinas Perhubungan Provinsi DKI Jakarta 2010 dalam Kompas, 27 Januari 2011). Kereta api dipilih karena bebas dari kemacetan, dapat mengangkut penumpang dan barang dalam jumlah besar dan murah. Dari segi lingkungan, kereta api adalah moda transportasi yang paling hemat. Kereta api lebih hemat energi 10x lipat dari pesawat terbang. Selain itu, kereta api bisa mengurangi lebih dari $70 \%$ bahan bakar yang diperlukan dan bisa mengurangi sampai $85 \%$ polusi dibandingkan pesawat terbang (http://perkeretaapian.dephub.go.id diakses 29 Oktober 2010).

Walaupun diminati oleh masyarakat, moda transportasi kereta api belumlah memuaskan. Hal ini sejalan dengan Survei Institut Studi Transportasi (Instran) yang dilakukan terhadap 367 responden yang menyebutkan bahwa pelayanan kereta api belum memuaskan (http://news.okezone.com diakses 29 Oktober 2010). Ketidakpuasan masyarakat muncul karena kereta api yang sering terlambat atau ditunda keberangkatannya, kondisi fisik kereta yang kurang baik dan ketidakjelasan informasi mengenai perjalanan kereta api kepada penumpang (Sunarto, 2009).

Selain itu, ketidakpuasan penumpang juga diakibatkan oleh maraknya tindak pelecehan seksual. Pelecehan seksual biasa menimpa kaum perempuan. Hal ini terbukti dari penelitian yang dilakukan oleh Indonesia Victimology Institute bekerja sama dengan Tokiwa International Victimology Institute (TIVI) Jepang pada April 2010. Penelitian tersebut menunjukkan bahwa dari 635 sampel orang yakni mahasiswa di Jakarta, sepertiga dari mahasiswa laki-laki (84 orang) pernah mengaku jadi korban pelecehan seksual. Sedangkan dua pertiga atau sebanyak 242 orang dari mahasiswi mengaku jadi korban pelecehan. Dari jumlah tersebut, delapan orang laki-laki serta 31 orang perempuan mengaku pernah mengalami pelecehan di transportasi umum (Susetyo,2010).

Di tengah ketidakpuasan yang dirasakan oleh penumpang akibat pelayanan kereta api yang buruk, pihak pengelola kereta api mencoba memberikan pelayanan baru kepada para penumpang wanita yakni dengan pengadaan gerbong khusus wanita. Gerbong khusus wanita ini dibuat dengan mengubah fungsi gerbong satu dan delapan dari satu rangkaian kereta. Pada awalnya gerbong satu dan delapan adalah gerbong yang mengangkut penumpang dengan berbagai jenis kelamin. Namun, sejak tanggal 19 Agustus 2010 kedua gerbong tersebut dikhususkan untuk kaum wanita. Pengadaan gerbong wanita ini dilakukan pada jenis kereta api listrik kelas Pakuan Ekspress dan Ekonomi AC. Gerbong wanita ini memiliki kapasitas menampung 150 penumpang.

Makalah ini membahas penelitian tentang gambaran kepuasan penumpang wanita terhadap adanya pelayanan kereta api gerbong khusus wanita dengan menggunakan pendekatan psikologi dan analisis data menggunakan statistika dan model Servqual.

\section{METODE PENELITIAN}

Dalam penelitian ini, metode yang digunakan adalah metode kuantitatif dengan jenis penelitiannya adalah penelitian deskriptif (descriptive research). Penelitian deskriptif ini bertujuan untuk memperoleh gambaran yang sistematis mengenai suatu gejala atau keadaan pada kelompok tertentu. (Hidajat, 2007).

\section{Operasionalisasi Variabel Penelitian}

Penelitian ini membahas mengenai analisa kepuasan penumpang terhadap pelayanan gerbong kereta api khusus wanita. Sehingga variabel-variabel yang ada dalam penelitian ini adalah pelayanan 
dan kepuasan. Definisi operasional dari kedua variabel tersebut, yaitu: Pelayanan adalah penyampaian jasa dari pihak pengelola kereta api kepada penumpang, sedangkan kepuasan adalah hasil pengukuran antara harapan dengan persepsi penumpang terhadap pelayanan.

\section{Jenis dan Sumber Data Penelitian}

Jenis dan sumber data yang digunakan untuk penelitian ada dua jenis yakni data primer dan data sekunder. Data primer adalah data yang diperoleh langsung dari sampel penelitian. Data sekunder adalah data mengenai sampel yang diperoleh secara tidak langsung (Hidajat,2007). Dalam penelitian ini data primer tersebut adalah hasil yang diperoleh dari penyebaran kuesioner kepada penumpang kereta api dengan jenis kelamin wanita. Sedangkan data sekunder didapatkan oleh peneliti melalui media elektronik, buku, jurnal dan sebagainya

\section{Teknik Pengumpulan Data}

Metode pengumpulan data adalah cara-cara yang digunakan oleh peneliti untuk mengumpulkan data. Untuk membantu dalam mengumpulkan data agar sistematis dan mudah digunakan instrumen pengumpulan data. Instrumen pengumpulan data ada berbagai jenis dan bentuk. Ada yang berupa angket, daftar cocok, lembar pengamatan,dll. (Arikunto,2000).

\section{Instrumen Penelitian}

Dalam penelitian ini, peneliti menggunakan metode angket atau kuesioner. Kuesioner dibuat oleh peneliti dengan mengacu kepada kuesioner pengukuran SERVQUAL oleh Cronin \& Taylor pada tahun 1992 (Tjiptono \& Candra, 2007) dan dikembangkan oleh peneliti berdasarkan pengamatan. Kuesioner ini bersifat tertutup. Kuesioner tertutup adalah kuesioner yang disajikan dalam bentuk sedemikian rupa sehingga responden tinggal memberikan tanda silang (x) pada kolom jawaban yang sesuai (Arikunto, 2000).

Kuesioner ini terdiri dari dua bagian yakni harapan dan persepsi. Bagian harapan dimaksudkan untuk mengukur sejauh mana harapan penumpang terhadap layanan kereta api. Sedangkan bagian persepsi bertujuan untuk mengukur sejauh mana pelayanan kereta api yang dirasakan oleh penumpang. Masing-masing bagian berisikan 63 pernyataan atau item baik positif maupun negatif. Untuk pilihan jawaban didasarkan pada skala Likert. Skala likert digunakan untuk mengukur sikap dari responden. Ada lima skala yang digunakan untuk pilihan jawaban responden yakni Sangat Setuju (SS), Setuju (S), Agak Setuju (AS), Tidak Setuju (TS), dan Sangat Tidak Setuju (STS). Masing-masing skala tersebut diberi bobot nilai yakni : Jawaban Sangat Setuju (SS) diberi nilai 5, Jawaban Setuju (S) diberi nilai 4, Jawaban Agak Setuju (AS) diberi nilai 3, Jawaban Kurang Setuju (KS) diberi nilai 2 dan Jawaban Sangat Tidak Setuju (STS) diberi nilai 1

\section{Validitas Instrumen}

Validitas adalah keadaan yang menggambarkan tingkat instrumen yang bersangkutan mampu mengukur apa yang diukur. Untuk mengetahui validitas instrumen dalam penelitian ini digunakan rumus product moment correlation sebagai berikut (Sugiyono,2010):

$$
\operatorname{rxy}=\frac{\mathrm{N}(\Sigma \mathrm{XY})-(\Sigma \mathrm{X} \Sigma \mathrm{Y})}{\sqrt{\left(\mathrm{N} \Sigma \mathrm{X}^{2}-(\Sigma \mathrm{X})^{2}\right)\left(\mathrm{N} \Sigma \mathrm{Y}^{2}-(\Sigma \mathrm{Y})^{2}\right)}}
$$


Keterangan:

Rxy : Koefisien korelasi skor ítem yang dicari validitasnya (x) dan skor total (y)

$\mathrm{N} \quad$ : Jumlah individu dalam sampel

$\Sigma X Y$ : Jumlah perkalian $\mathrm{X}$ dan $\mathrm{Y}$

$\Sigma X^{2} \quad$ : Jumlah kuadrat masing-masing skor $X$

$\Sigma \mathrm{Y}^{2}$ : Jumlah kuadrat masing-masing skor $\mathrm{Y}$

$\Sigma \mathrm{X}$ : Jumlah skor dalam distribusi $\mathrm{X}$

$\Sigma \mathrm{Y} \quad$ : Jumlah skor dalam distribusi Y

\section{Reliabilitas Instrumen}

Reliabilitas adalah suatu pengukuran yang menunjukkan seberapa konsisten suatu pengukuran dilakukan. Dalam penelitian ini digunakan teknik reabilitas yakni dengan rumus Cronbach Alpha (Supriyatmini,2005). Namun untuk pengerjaannya menggunakan program SPSS for Windows versi 16.

\section{Pengambilan Sampel}

Untuk penelitian ini, populasinya adalah penumpang kereta api. Sedangkan sampelnya adalah penumpang kereta api berjenis kelamin wanita yang menggunakan dan yang pernah merasakan gerbong kereta api khusus wanita. Teknik pengambilan sampel yang digunakan adalah incidental sampling dengan pengambilan data dilakukan awal bulan Januari 2011 berlokasi di stasiun dan di dalam gerbong kereta api khusus wanita dengan rute perjalanan dari Bogor ke Jakarat (PP).

\section{Pengolahan Data}

Pengolahan data yang dilakukan dalam penelitian ini yaitu model SERVQUAL. Penggunaan model ini menganalisis kesenjangan antara dua varibel pokok yakni jasa yang diharapkan dan jasa yang dipersepsikan (Tjiptono \& Chandra,2007). Sebelum menentukan nilai dari SERVQUAL, maka harus dicari nilai-nilai sebagai berikut:

1. Rumus untuk menghitung nilai harapan dan persepsi, yakni (Muryani,2009):

2 .

$$
\mathrm{SEi} / \mathrm{SPi}=\frac{(\mathrm{E} 1 \times 1)+(\mathrm{E} 2 \times 2)+(\mathrm{E} 3 \times 3)+(\mathrm{E} 4 \times 4)+(\mathrm{E} 5 \times 5)}{\mathrm{N}}
$$

Keterangan:

$\mathrm{SEi}=$ Skor harapan responden terhadap atribut pelayanan $\mathrm{i}$

$\mathrm{SPi}=$ Skor persepsi responden terhadap atribut pelayanan $\mathrm{i}$

$\mathrm{E} 1$ = Jumlah responden dengan jawaban "Sangat Tidak Setuju"

$\mathrm{E} 2$ = Jumlah responden dengan jawaban "Setuju"

$\mathrm{E} 3$ = Jumlah responden dengan jawaban "Agak Setuju"

$\mathrm{E} 4=$ Jumlah responden dengan jawaban "Tidak Setuju"

E5 = Jumlah responden dengan jawaban "Sangat Tidak Setuju"

$\mathrm{N}=$ Total responden

3. Rumus menghitung nilai harapan dan persepsi pada masing-masing dimensi kualitas pelayanan:

$$
\frac{\sum_{\mathrm{i}=1}^{\mathrm{nj}} \mathrm{TEij}}{\mathrm{Nj}}
$$


Keterangan:

Eij $=$ Skor harapan responden pada dimensi $\mathrm{j}$

$\mathrm{TEij}=$ Skor harapan responden terhadap atribut pelayanan $\mathrm{i}$

$\mathrm{Nj}=$ Jumlah atribut pada dimensi $\mathrm{j}$

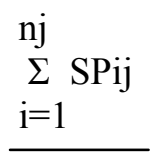

$\mathrm{Nj}$

Keterangan

$\mathrm{Pij}=$ Skor persepsi responden pada dimensi $\mathrm{j}$

$\mathrm{SPij}=$ Skor persepsi responden terhadap atribut pelayanan $\mathrm{i}$

$\mathrm{nj}=$ Jumlah atribut dalam dimensi $\mathrm{j}$

4. Rumus perhitungan nilai kesenjangan antara harapan dan persepsi (SERVQUAL)

$$
\text { SERVQUAL }=\text { Skor Persepsi }(\mathrm{Pij})-\text { Skor Harapan }(\text { Eij })
$$

\section{HASIL DAN PEMBAHASAN}

\section{Hasil}

Responden penelitian ini adalah penumpang kereta api Bogor-Jakarta (PP) berjumlah 80 orang. Responden berusia antara 12 sampai 49 tahun dengan jenis kelamin wanita. Responden memiliki karakteristik yang berbeda dan bervariasi berdasarkan pendidikan terakhir mulai dari Sekolah Dasar (SD) hingga Strata Dua (S2), bidang pekerjaan ada dari Pegawai Negeri Sipil (PNS)/Tentara Nasional Indonesia (TNI)/Polisi Republik Indonesia (Polri), pelajar/mahasiswa, pegawai swasta/wiraswasta, Selain itu variasi responden terlihat dari jenis kereta api yang digunakan dan frekuensi menggunakan kereta api. Sebaran profil dari responden penelitian kepuasan sbb:

Tabel 1 Tingkat Pendidikan

pendidikan

\begin{tabular}{|c|c|c|c|c|c|}
\hline & & Frequency & Percent & Valid Percent & $\begin{array}{l}\text { Cumulative } \\
\text { Percent }\end{array}$ \\
\hline \multirow[t]{7}{*}{ Valid } & sd & 3 & 3,8 & 3,8 & 3,8 \\
\hline & smp & 2 & 2,5 & 2,5 & 6,3 \\
\hline & sma & 35 & 43,8 & 43,8 & 50,0 \\
\hline & d3 & 13 & 16,3 & 16,3 & 66,3 \\
\hline & s1 & 25 & 31,3 & 31,3 & 97,5 \\
\hline & s2 & 2 & 2,5 & 2,5 & 100,0 \\
\hline & Total & 80 & 100,0 & 100,0 & \\
\hline
\end{tabular}

Sumber: Hasil Pengolahan Data

Dari tabel di atas menunjukkan bahwa dari 80 responden yang tingkat pendidikan terakhirnya SD sebanyak tiga orang atau 3,8\%. Pendidikan terakhir SMP sebanyak dua orang atau sebesar 2,5\%. SMA 35 orang atau 43,8 \%, D3 sebanyak 13 orang atau 16,3\%, S1 sebanyak 13 orang atau 31,3\%, S2 sebanyak 2 orang atau 2,5\% dan tidak ada yang memiliki pendidikan akhir S3. Sedangkan profil responden berdasarkan pekerjaan seperti pada tabel 2 
Tabel 2 Pekerjaan

\begin{tabular}{|c|c|c|c|c|c|}
\hline \multicolumn{6}{|c|}{ pekerjaan } \\
\hline & & Frequency & Percent & Valid Percent & $\begin{array}{l}\text { Cumulative } \\
\text { Percent }\end{array}$ \\
\hline \multirow[t]{5}{*}{ Valid } & pns/tni/polri & 5 & 6,3 & 6,3 & 6,3 \\
\hline & pelajar/mahasiswa & 38 & 47,5 & 47,5 & 53,8 \\
\hline & $\begin{array}{l}\text { pegawai } \\
\text { swasta/wiraswasta }\end{array}$ & 31 & 38,8 & 38,8 & 92,5 \\
\hline & lainnya & 6 & 7,5 & 7,5 & 100,0 \\
\hline & Total & 80 & 100,0 & 100,0 & \\
\hline
\end{tabular}

Sumber: Hasil Pengolahan Data

Dari tabel 2 diperoleh hasil bahwa responden yang paling banyak mengisi kuesioner dilihat dari jenis pekerjaannya yakni pelajar/mahasiswa dengan jumlah 38 orang atau sebesar $47,5 \%$. Responden dengan jumlah besar kedua adalah orang-orang yang bekerja sebagai pegawai swasta/wiraswasta yakni sebanyak 31 orang atau $38,8 \%$. Sisanya adalah responden yang memiliki pekerjaan pns/tni/polri dan lainnya dengan persentase masing-masing sebesar $6,3 \%$ dan 7,5\%. Kemudian profil responden berdasarkan jenis kereta adalah sebagai berikut:

Tabel 3 Jenis kereta

jenis krl

\begin{tabular}{|c|c|c|c|c|c|}
\hline & & Frequency & Percent & Valid Percent & $\begin{array}{l}\text { Cumulative } \\
\text { Percent }\end{array}$ \\
\hline \multirow[t]{4}{*}{ Valid } & ekonomi ac & 50 & 62,5 & 62,5 & 62,5 \\
\hline & ekspress pakuan & 20 & 25,0 & 25,0 & 87,5 \\
\hline & lainnya & 10 & 12,5 & 12,5 & 100,0 \\
\hline & Total & 80 & 100,0 & 100,0 & \\
\hline
\end{tabular}

Sumber: Hasil Pengolahan Data

Dari tabel 3 terlihat responden yang menggunakan kereta kelas ekonomi AC sebanyak 50 orang $(62,5 \%)$, kereta ekspress pakuan sebanyak 20 orang $(25 \%)$ dan yang lainnya yakni kereta api kelas ekonomi sebanyak 10 orang (12,5\%).

\section{Analisis Data}

\section{Uji Kecukupan Data}

Pada tahap awal, kuesioner disebarkan 40 responden dengan tujuan untuk melihat apakah pertanyaan-pertanyaan dalam kuesioner tersebut dapat dipahami dan tidak membingungkan. Dari 40 kuesioner yang disebar terdapat 2 buah kuesioner dinyatakan rusak karena dalam pengisiannya tidak lengkap. Jadi, secara umum kuesioner sudah dianggap benar dan siap untuk proses pengolahan data selanjutnya.

Langkah selanjutnya adalah menguji kecukupan data dari kuesioner awal tersebut dengan menggunakan rumus Bernoulli (Nurdiyanto,2008):

$$
\mathrm{N}=\frac{\left[\mathrm{Z}_{(\alpha / 2)}\right]^{2} \mathrm{p} \cdot \mathrm{q}}{\mathrm{e}^{2}}
$$

dimana :

$\mathrm{N}=$ Jumlah sampel minimum

$\mathrm{Z}=$ Nilai distribusi normal 
$\mathrm{e}=$ toleransi error $(5 \%=0,05)$

$\mathrm{p}=$ persentasi kuesioner dijawab benar

$\mathrm{q}=$ persentasi kuesioner dijawab salah.

Dengan menggunakan tingkat kesalahan yang dapat diterima sebesar 5\% atau tingkat kepercayaan sebesar $95 \%$, maka diperoleh :

$$
\begin{aligned}
& \mathrm{P}=38 / 40=0,95 \quad ; \mathrm{q}=4 / 40=0,05 \quad ; \mathrm{e}=5 \%=0,05 \\
& (\alpha / 2)=(0,05 / 2)=0,025 \quad ; Z(\alpha / 2)=Z(0,025)=1,96 \text { sehingga nilai } N \text { adalah } \\
& \mathrm{N}=\frac{(1,96)^{2}(0,95)(0,05)}{(0,05)^{2}} \quad=72,9=73 \text { data }
\end{aligned}
$$

Dengan demikian diperlukan sebanyak minimal 73 responden untuk mengisi kusioner berikutnya tetapi dalam penelitian ini diambil 80 data responden sebagai jumlah data penelitian. Hal ini dilakukan untuk memberikan hasil penelitian yang terbaik.

\section{Uji Validitas Data}

Tujuan dari pengujian validitas data adalah untuk mengetahui keakuratan kusioner yang disebarkan. Uji validitas awal pada penelitian ini menggunakan taraf signifikan $5 \%$ dan $\mathrm{N}=38$ sampel maka $\mathbf{r}$ tabel $=\mathbf{0 , 3 2}$. Dari hasil perhitungan uji validitas kuesioner awal untuk 38 sampel responden dengan 70 item pernyataan ternyata ada sebanyak 7 pernyataan yang tidak valid yaitu item pernyataan $11,15,21,41,50,57$ dan 69 , kemudian sesuai dengan aturan pada uji ini maka data item yang tidak valid dibuang agar menghasilkan uji yang lebih baik. Tahap berikutnya adalah memperbaiki pernyataan-pernyataan pada kuesioner sebelumnya dengan membuang ketujuh pernyataan di atas, kemudian kuesioner kembali disebarkan ke responden sebanyak 80 responden sesuai dengan hasil perhitungan kecukupan data sebelumnya. Uji validitas data ini juga menggunakan taraf signifikan 5\% dengan $\mathrm{N}=80$ sampel sehingga diperoleh nilai $\mathrm{r}$ tabel sebesar 0,220. Dalam pengujian validitas data dilakukan dengan membandingkan nilai $r$ hitung dengan nilai $r$ tabel.

Data dikatakan valid jika nilai $r$ hitung lebih besar dari $r$ tabel dan sebaliknya data dikatakan tidak valid jika nilai $r$ hitung lebih kecil dari $r$ tabel. Setelah dilakukan perhitungan sesuai dengan rumusan yang diuraikan sebelumnya dengan menggunakan product moment correlation untuk data yang dikumpulkan, diperoleh hasil seperti pada tabel Uji Validitas Data yang tersaji di lembar lampiran.

\section{Uji Reliabilitas Data}

Uji reliabilitas data dalam penelitian ini dilakukan dengan menggunakan reliability analysis, Chronbach alpha. Data dikatakan memiliki reliabilitas yang tinggi apabila nilai koefisien yang diperoleh $>0,60$ (Ghozali,2002). Hasil analisis data penelitian ini diperoleh nilai alpha pengalaman dan harapan masing-masing sebesar 0,967 dan 0,979 yang berarti reliabel karena nilai hasil perhitungan lebih besar dari standard 0,6.

\section{Perhitungan Nilai Kesenjangan Persepsi dan Harapan (SERVQUAL) per Dimensi}

Hasil dari perhitungan nilai kesenjangan antara persepsi dan harapan (SERVQUAL) per item dikelompokkan ke delapan dimensi. Kemundian dihitung nilai rata-rata SERVQUAL, maka diperoleh hasil nilai kesenjangan antara persepsi dan harapan (SERVQUAL) per dimensi yang tersaji pada Tabel 4 
Tabel 4 Nilai Kesenjangan antara Persepsi dan Harapan (SERVQUAL) per Dimensi

\begin{tabular}{|c|c|c|c|c|}
\hline $\begin{array}{l}\text { No } \\
\text { item }\end{array}$ & Item/Pernyataan & Persepsi & Harapan & SERVQUAL \\
\hline & Dimensi Bukti Fisik & & & \\
\hline 1 & $\begin{array}{l}\text { Kereta api yang beroperasi adalah kereta api model dan } \\
\text { teknologi terbaru }\end{array}$ & 2,6375 & 4,0875 & \\
\hline 5 & Toilet yang ada di stasiun bersih dan wangi & 2,4375 & 3,7875 & \\
\hline 11 & $\begin{array}{l}\text { Bangunan stasiun kereta api khususnya stasiun daerah } \\
\text { Bogor-Jakarta Kota/Tanah Abang merupakan bangunan } \\
\text { baru }\end{array}$ & 2,5875 & 3,45 & \\
\hline 16 & $\begin{array}{l}\text { Semua bangunan stasiun kereta api khususnya daerah } \\
\text { Bogor-Jakarta Kota /Tanah Abang dalam kondisi } \\
\text { terawat }\end{array}$ & 2,625 & 3,8875 & \\
\hline 25 & $\begin{array}{l}\text { Di stasiun terdapat papan pem-beritahuan tentang } \\
\text { jadwal kedatangan dan keberangkatan kereta api }\end{array}$ & 3,3 & 4,3625 & \\
\hline 32 & $\begin{array}{l}\text { Di stasiun terdapat iklan atau pamflet yang berisi } \\
\text { tentang informasi gerbong khusus wanita }\end{array}$ & 3,5625 & 4,25 & \\
\hline 35 & $\begin{array}{l}\text { Di semua stasiun wilayah Bogor-Jakarta Kota/Tanah } \\
\text { Abang memiliki fasilitas toilet }\end{array}$ & 3,4125 & 4,35 & \\
\hline 38 & $\begin{array}{l}\text { Di setiap peron stasiun terdapat area tunggu khusus } \\
\text { untuk penumpang wanita yang naik ke dalam gerbong } \\
\text { khusus wanita }\end{array}$ & 2,725 & 3,975 & \\
\hline 49 & $\begin{array}{l}\text { Kondisi di dalam gerbong khusus wanita bersih dan rapi } \\
\text { (tidak ada sampah yang berserakan) }\end{array}$ & 3,1375 & 4,2875 & \\
\hline 62 & $\begin{array}{l}\text { Di dalam gerbong khusus wanita disediakan tempat } \\
\text { untuk ibu menyusui }\end{array}$ & 2,475 & 3,9875 & \\
\hline \multirow[t]{3}{*}{63} & $\begin{array}{l}\text { Petugas kereta yang ada di stasiun dan di dalam } \\
\text { gerbong khusus wanita berpakaian rapi dan seragam }\end{array}$ & 3,6625 & 4,0625 & \\
\hline & JUMLAH & 2,960 & 4,044 & $-1,084$ \\
\hline & Dimensi Reliabilitas & & & \\
\hline 3 & $\begin{array}{l}\text { Pihak pengelola kereta api selalu menepati janji yang } \\
\text { telah dibuat terkait dengan pembenahan layanan }\end{array}$ & 2,45 & 3,9125 & \\
\hline 8 & $\begin{array}{l}\text { Pengelola kereta api menyediakan layanan gerbong } \\
\text { khusus wanita di seluruh rangkaian kereta api di } \\
\text { Indonesia }\end{array}$ & 2,6875 & 4,125 & \\
\hline 15 & $\begin{array}{l}\text { Jumlah gerbong wanita dalam rangkaian kereta sudah } \\
\text { cukup memenuhi kebutuhan penumpang wanita }\end{array}$ & 2,4875 & 3,4875 & \\
\hline 31 & $\begin{array}{l}\text { Harga karcis kereta api sesuai dengan dengan } \\
\text { pelayanan yang diberikan }\end{array}$ & 2,875 & 4,1 & \\
\hline 42 & Pengelola kereta api dapat dipercaya dan diandalkan & 2,675 & 4,175 & \\
\hline 46 & $\begin{array}{l}\text { Sewaktu penumpang mendapatkan masalah (spt. } \\
\text { kehilangan barang di dalam kereta, dll) Pihak pengelola } \\
\text { kereta api bersikap simpatik dan mampu menenangkan } \\
\text { penumpang }\end{array}$ & 3,0125 & 4,1375 & \\
\hline 50 & $\begin{array}{l}\text { Petugas kereta api selalu memberitahukan kepada } \\
\text { penumpang tentang keberadaan gerbong wanita pada } \\
\text { setiap rangkaian KRL }\end{array}$ & 3,45 & 4,325 & \\
\hline 52 & $\begin{array}{l}\text { Sewaktu pengelola kereta api berjanji untuk membenahi } \\
\text { layanan yang diberikan, hal tersebut diberikan tepat } \\
\text { waktu }\end{array}$ & 2,45 & 4,1625 & \\
\hline 55 & $\begin{array}{l}\text { Pengelola kereta api menyampaikan jasanya sesuai } \\
\text { dengan waktu yang dijanjikan }\end{array}$ & 2,65 & 3,8875 & \\
\hline 58 & Kereta api datang dan berangkat tepat waktu & 2,475 & 4,225 & \\
\hline \multirow[t]{2}{*}{61} & Kereta api sering mogok di tengah jalan & 2,625 & 3,525 & \\
\hline & JUMLAH & 2,713 & 4,006 & $-1,293$ \\
\hline
\end{tabular}


Tabel 4 Nilai Kesenjangan antara Persepsi dan Harapan (SERVQUAL) per Dimensi (lanjutan)

\begin{tabular}{|c|c|c|c|c|}
\hline $\begin{array}{l}\text { No } \\
\text { item }\end{array}$ & Item/Pernyataan & Persepsi & Harapan & SERVQUAL \\
\hline & Dimensi Daya Tanggap & & & \\
\hline 4 & $\begin{array}{l}\text { Apabila ada penumpang wanita yang memerlukan } \\
\text { bantuan petugas langsung menghampiri }\end{array}$ & 3,3125 & 4,2625 & \\
\hline 6 & $\begin{array}{l}\text { Apabila ada penumpang yang tersesat atau } \\
\text { kebingungan di dalam stasiun petugas langsung } \\
\text { membantu }\end{array}$ & 3,25 & 4,275 & \\
\hline 10 & $\begin{array}{l}\text { Penumpang selalu mendapatkan informasi terbaru dan } \\
\text { cepat tentang perubahan jadwal kereta api }\end{array}$ & 2,55 & 4,1625 & \\
\hline 14 & $\begin{array}{l}\text { Apabila ada penumpang laki-laki yang salah masuk di } \\
\text { gerbong wanita, petugas langsung menghampiri dan } \\
\text { meminta penumpang tersebut pindah ke gerbong umum }\end{array}$ & 4,0375 & 4,4875 & \\
\hline 20 & $\begin{array}{l}\text { Pengaduan atau protes penumpang terhadap layanan } \\
\text { yang diberikan segera ditanggapi oleh pengelola kereta }\end{array}$ & 2,4375 & 4,05 & \\
\hline \multirow[t]{3}{*}{36} & $\begin{array}{l}\text { Petugas selalu memberikan informasi yang benar dan } \\
\text { jelas kepada penumpang tentang waktu kedatangan dan } \\
\text { keberangkatan kereta di stasiun }\end{array}$ & 2,825 & 4,2625 & \\
\hline & JUMLAH & 3,069 & 4,250 & $-1,181$ \\
\hline & Dimensi Jaminan & & & \\
\hline 2 & $\begin{array}{l}\text { Tindakan kejahatan terhadap wanita berkurang sejak } \\
\text { adanya gerbong wanita }\end{array}$ & 3,6125 & 4,2125 & \\
\hline 13 & $\begin{array}{l}\text { Petugas di gerbong khusus wanita bersikap ramah dan } \\
\text { sopan }\end{array}$ & 3,55 & 4,325 & \\
\hline 22 & $\begin{array}{l}\text { Setiap memasuki gerbong wanita, petugas selalu } \\
\text { memberikan salam kepada penumpang }\end{array}$ & 2,2625 & 3,65 & \\
\hline 26 & $\begin{array}{l}\text { Apabila ada perbaikan kereta api sehingga beberapa } \\
\text { perjalanan kereta dibatalkan atau ditunda, maka pihak } \\
\text { pengelola kereta api memberitahukan kepada } \\
\text { penumpang sehari sebelumnya }\end{array}$ & 2,2875 & 4,0125 & \\
\hline 30 & $\begin{array}{l}\text { Petugas bersikap sopan saat memeriksa karcis } \\
\text { penumpang }\end{array}$ & 3,425 & 4,4 & \\
\hline 33 & $\begin{array}{l}\text { Setelah sampai di stasiun tujuan, penumpang disambut } \\
\text { ramah oleh petugas stasiun }\end{array}$ & 2,675 & 3,9125 & \\
\hline 37 & $\begin{array}{l}\text { Petugas keamanan di gerbong khusus wanita mampu } \\
\text { melindungi wanita }\end{array}$ & 3,2625 & 4,3625 & \\
\hline 40 & $\begin{array}{l}\text { Apabila ada penumpang laki-laki yang salah masuk ke } \\
\text { gerbong wanita, petugas menegur dengan sopan }\end{array}$ & 3,7625 & 4,3625 & \\
\hline 43 & $\begin{array}{l}\text { Apabila terjadi kerusakan kereta api saat melakukan } \\
\text { perjalanan,petugas langsung memberikan penjelasan } \\
\text { kepada penumpang }\end{array}$ & 3,05 & 4,4 & \\
\hline 44 & $\begin{array}{l}\text { Di setiap stasiun ada polisi khusus kereta api (poluska) } \\
\text { yang menjaga keamanan di stasiun }\end{array}$ & 3,0625 & 4,3 & \\
\hline 47 & $\begin{array}{l}\text { Penumpang merasa aman dan nyaman saat berada di } \\
\text { dalam gerbong wanita }\end{array}$ & 3,7125 & 4,4125 & \\
\hline 51 & $\begin{array}{l}\text { Penumpang merasa aman saat menggunakan kereta } \\
\text { sebagai alat transportasi }\end{array}$ & 3,125 & 4,2875 & \\
\hline 54 & $\begin{array}{l}\text { Kondisi di dalam gerbong khusus wanita gelap dan } \\
\text { menakutkan }\end{array}$ & 3,9375 & 3,875 & \\
\hline \multirow[t]{2}{*}{57} & $\begin{array}{l}\text { Petugas selalu menjaga pintu masuk gerbong khusus } \\
\text { wanita agar tidak dinaiki penumpang laki-laki }\end{array}$ & 3,5625 & 4,3375 & \\
\hline & JUMLAH & 3,235 & 4,204 & $-0,969$ \\
\hline
\end{tabular}


Tabel 4 Nilai Kesenjangan antara Persepsi dan Harapan (SERVQUAL) per Dimensi (lanjutan)

\begin{tabular}{|c|c|c|c|c|}
\hline $\begin{array}{l}\text { No } \\
\text { item }\end{array}$ & Item/Pernyataan & Persepsi & Harapan & SERVQUAL \\
\hline & Dimensi Empati & & & \\
\hline 7 & $\begin{array}{l}\text { Pengelola kereta api memahami benar kebutuhan } \\
\text { penumpang khususnya penumpang wanita }\end{array}$ & 2,975 & 4,1125 & \\
\hline 12 & $\begin{array}{l}\text { Kepentingan penumpang khususnya wanita menjadi } \\
\text { prioritas utama pengelola kereta api }\end{array}$ & 2,875 & 3,975 & \\
\hline 18 & $\begin{array}{l}\text { Petugas kereta api memberikan perhatian kepada setiap } \\
\text { penumpang }\end{array}$ & 2,7375 & 4,0625 & \\
\hline 24 & $\begin{array}{l}\text { Petugas kereta api melayani seluruh penumpang tanpa } \\
\text { terkecuali }\end{array}$ & 3,3875 & 4,2125 & \\
\hline 28 & $\begin{array}{l}\text { Petugas keretaapi membantu penumpang yang } \\
\text { kesulitan saat hendak naik ke dalam gerbong khusus } \\
\text { wanita }\end{array}$ & 3,1 & 4,175 & \\
\hline 39 & $\begin{array}{l}\text { Pelayanan yang diberikan petugas terhadap penumpang } \\
\text { tidak membedakan status sosial }\end{array}$ & 3,4875 & 4,3375 & \\
\hline 48 & Semua penumpang diperlakukan layaknya raja & 2,6375 & 3,725 & \\
\hline \multirow[t]{2}{*}{60} & $\begin{array}{l}\text { Semua penumpang diperlakukan adil oleh petugas } \\
\text { kereta api }\end{array}$ & 3,4625 & 4,3625 & \\
\hline & JUMLAH & 3,083 & 4,120 & $-1,037$ \\
\hline 41 & $\begin{array}{l}\text { Dimensi Kenyamanan } \\
\text { Di setiap area tunggu khusus penumpang wanita yang } \\
\text { ada di peron stasiun tersedia tempat duduk yang } \\
\text { nyaman }\end{array}$ & 2,75 & 4,2 & \\
\hline 45 & Lampu di dalam gerbong khusus wanita berfungsi baik & 3,6375 & 4,2625 & \\
\hline 56 & $\begin{array}{l}\text { Tempat duduk di dalam gerbong khusus wanita empuk } \\
\text { dan nyaman }\end{array}$ & 3,5875 & 4,25 & \\
\hline \multirow[t]{3}{*}{59} & $\begin{array}{l}\text { Pendingin udara di gerbong khusus wanita (AC\&kipas } \\
\text { angin) berfungsi dengan baik }\end{array}$ & 3,4875 & 4,3125 & \\
\hline & JUMLAH & 3,366 & 4,256 & $-0,89$ \\
\hline & Dimensi Koneksi & & & \\
\hline 19 & Rangkaian kereta selalu tersedia di stasiun & 2,6625 & 4,0375 & \\
\hline \multirow[t]{3}{*}{21} & Fasilitas tempat parkir di semua stasiun luas dan mudah & 2,6625 & 3,925 & \\
\hline & JUMLAH & 2,662 & 3,981 & $-1,319$ \\
\hline & Dimensi Kemudahan & & & \\
\hline 9 & $\begin{array}{l}\text { Di stasiun tersedia loket karcis yang khusus melayani } \\
\text { penumpang gerbong khusus wanita }\end{array}$ & 2,3375 & 3,6375 & \\
\hline 17 & $\begin{array}{l}\text { Sikap petugas di loket pembelian karcis sopan dan } \\
\text { ramah }\end{array}$ & 2,725 & 4,075 & \\
\hline 23 & Karcis kereta mudah didapat & 3,6875 & 4,3375 & \\
\hline 27 & Harga karcis terjangkau untuk semua kalangan & 3,075 & 4,225 & \\
\hline 29 & $\begin{array}{l}\text { Setiap masuk stasiun, penumpang dengan mudah } \\
\text { menemukan loket pembelian karcis }\end{array}$ & 3,6875 & 4,3625 & \\
\hline 34 & Harga karcis kereta api masih dalam batas kewajaran & 3,3875 & 4,125 & \\
\hline \multirow[t]{2}{*}{53} & $\begin{array}{l}\text { Petugas di dalam kereta api selalu memberikan } \\
\text { informasi mengenai lamanya waktu perjalanan dari } \\
\text { stasiun Bogor-Jakarta }\end{array}$ & 2,4375 & 3,8125 & \\
\hline & JUMLAH & 3,048 & 4,082 & $-1,034$ \\
\hline
\end{tabular}

Sumber: Hasil Pengolahan Data

\section{Perhitungan Nilai Kesenjangan Persepsi dan Harapan (SERVQUAL) secara keseluruhan}

Hasil perhitungan nilai kesenjangan antara persepsi dan harapan (SERVQUAL) secara keseluruhan menunjukkan sampai sejauh mana pihak pengelola kereta api memberikan pelayanannya terhadap penumpang secara keseluruhan. Berdasarkan Tabel 5, diperoleh hasil nilai SERVQUAL yang bertanda negatif. Semakin negatif atau rendah nilai SERVQUAL maka kualitas pelayanan akan berkurang di mata konsumen (Zeithaml, Parasuraman \& Berry, 1990). Dapat dikatakan bahwa penumpang memiliki pandangan yang rendah terhadap kualitas pelayanan gerbong kereta api khusus wanita. 
Tabel 5 Tabel Perhitungan Nilai Kesenjangan antara Persepsi dan Harapan (SERVQUAL) secara keseluruhan

\begin{tabular}{llccc}
\multicolumn{5}{c}{ antara Persepsi dan Harapan (SERVQUAL) secara keseluruhan } \\
\hline NO & DIMENSI & PERSEPSI & HARAPAN & SERVQUAL \\
\hline 1 & Bukti fisik & 2,960 & 4,044 & $-1,084$ \\
2 & Reliabilitas & 2,713 & 4,006 & $-1,293$ \\
3 & Daya Tanggap & 3,069 & 4,250 & $-1,181$ \\
4 & Jaminan & 3,235 & 4,204 & $-0,969$ \\
5 & Empati & 3,083 & 4,120 & $-1,037$ \\
6 & Kenyamanan & 3,366 & 4,256 & $-0,89$ \\
7 & Koneksi & 2,662 & 3,981 & $-1,319$ \\
8 & Kemudahan & 3,048 & 4,082 & $-1,034$ \\
\hline
\end{tabular}

Sumber: Hasil Pengolahan Data

\section{Pengukuran Kepuasan Penumpang}

Pengukuran kepuasan penumpang dilakukan dengan merata-ratakan perbandingan antara harapan dan pengalaman. Hasil penilaian mengenai produk atau jasa dengan menggunakan rumus (Sugiyono,2010): Kp $=\mathrm{Pp} / \mathrm{Ex}$

Dimana: $\mathrm{Kp}=$ Kepuasan $; \mathrm{Pp}=$ Pengalaman $; \quad E x=$ Harapan

Penumpang dikatakan puas apabila harapannya terpenuhi dan tidak puas bila harapan tidak terpenuhi. Dengan menggunakan interval seperti yang dijelaskan di bawah ini sebaran kepuasan dan ketidakpuasan menjadi lebih jelas. Terdapat pemecahan kriteria menjadi 5 (lima) kategori interval sbb:
1. Sangat tidak puas
kategori 1
$0,0 \mathrm{~s} / \mathrm{d} \quad 0,50$
2. Tidak puas
kategori $2 \quad 0,51 \mathrm{~s} / \mathrm{d} 0,74$
3. Cukup puas
kategori $3 \quad 0,75 \mathrm{~s} / \mathrm{d}$ 0,99
4. Puas
kategori $4 \quad 1$
5. Sangat puas
kategori $5>1$

Tabel 7 Tabel Kepuasan Penumpang

\begin{tabular}{llcccc}
\hline NO & DIMENSI & PERSEPSI & HARAPAN & KEPUASAN & Ranking \\
\hline 1 & Bukti fisik & 2,960 & 4,044 & 0,73 & 4 \\
2 & Reliabilitas & 2,713 & 4,006 & 0,68 & 2 \\
3 & Daya Tanggap & 3,069 & 4,250 & 0,72 & 3 \\
4 & Jaminan & 3,235 & 4,204 & 0,77 & 7 \\
5 & Empati & 3,083 & 4,120 & 0,75 & 5 \\
6 & Kenyamanan & 3,366 & 4,256 & 0,79 & 8 \\
7 & Koneksi & 2,662 & 3,981 & 0,67 & $\mathbf{6}$ \\
8 & Kemudahan & 3,048 & 4,082 & 0,75 & \\
\hline & JUMLAH & $\mathbf{2 4 , 1 3 6 / 8}$ & $\mathbf{3 2 , 9 4 3 / 8}$ & $\mathbf{0 , 7 3}$ & \\
\hline
\end{tabular}

Sumber: Hasil Pengolahan Data

Dengan memperhatikan Tabel 7. pada kolom $\mathrm{Kp}=$ Kepuasan, terlihat bahwa secara ratarata penumpang kereta api gerbong khusus wanita tidak puas. Hal ini ditunjukkan dari nilai ratarata yang diperoleh sebesar 0,73 yang mengacu pada kategori 2. Selain itu, dalam Tabel 7. terdapat kolom ranking. Kolom ini merepresentasikan level kepuasan penumpang terhadap delapan dimensi tersebut. Urutan atau ranking pertama yang memiliki level kepuasan terendah terletak pada dimensi koneksi. Di urutan kedua ada dimensi reliabilitas. Selanjutnya di urutan ketiga sampai delapan ada dimensi daya tanggap, bukti fisik empati, kemudahan, jaminan, dan kenyamanan. 


\section{Pembahasan}

\section{Profil Responden}

Berdasarkan data yang diperoleh, responden dalam penelitian ini memiliki karakteristik yang beragam. Apabila ditinjau dari pendidikan terakhir, jumlah responden yang banyak terlibat adalah orang-orang yang memiliki pendidikan akhir SMA dan S1 yakni sebanyak 35 orang $(43,8 \%)$ dan 25 orang $(31,3 \%)$. Hal ini disebabkan karena pernyataan di kuesioner lebih mudah dipahami oleh orang yang tingkat pendidikannya cukup tinggi seperti SMA dan S1 dibandingkan orang yang pendidikan akhirnya SD atau SMP. Dari sisi pekerjaan, ada dua pekerjaan yang paling dominan menjadi responden dalam penelitian ini. Jumlah terbanyak adalah pelajar/mahasiswa sebesar 47,5\%. Hal ini terjadi karena jalur kereta api rute Bogor-Jakarta melewati daerah-daerah yang banyak terdapat institusi pendidikan (sekolah maupun perguruan tinggi). Contohnya Universitas Indonesia,Universitas Pancasila ,dll. Sedangkan urutan kedua adalah orang yang pekerjaannya sebagai pegawai swasta/wiraswasta karena banyak pegawai memiliki lokasi tempat tinggal yang cukup jauh dari tempat mereka bekerja. Misalnya mereka bekerja di Jakarta tetapi bertempat tinggal di daerah Depok.

Berdasarkan jenis kereta yang digunakan, hasil yang diperoleh untuk pengguna kereta ekonomi AC sebanyak 50 orang (62,5 \%),kereta ekspres Pakuan berjumlah 20 orang (25\%). Sedangkan untuk jenis kereta lainnya seperti ekonomi hanya 10 orang $(12,5 \%)$. Jumlah tersebut diperoleh karena sampel penelitian ini adalah penumpang wanita yang menggunakan dan pernah merasakan gerbong kereta api khusus wanita yang hanya ada pada rangkaian kereta api ekonomi AC dan Ekspres Pakuan. Untuk segi usia atau umur, responden paling banyak jumlahnya adalah usia 2130 tahun yakni sebanyak 46 orang atau sebesar 57,5\%. Hal ini dikarenakan usia antara 21-30 tahun yang dalam perkembangan manusia termasuk kategori dewasa (adulthood) adalah usia yang produktif. Mereka banyak melakukan aktivitas di luar rumah seperti kuliah dan kerja sehingga menggunakan kereta api untuk menuju tempat beraktivitas. Sedangkan ditinjau dari segi frekuensi naik kereta api, didapatkan hasil sebanyak 54 orang atau $(67,5 \%)$ sering menggunakan kereta api sebagai moda transportasinya. Jumlah ini dapat merepresentasikan hasil kepuasan penumpang yang lebih akurat karena intensitas mereka dalam merasakan pelayanan kereta api lebih intens.

\section{Kepuasan}

Kepuasan penumpang muncul akibat harapan yang terpenuhi oleh pengelola kereta api. Sedangkan ketidakpuasan muncul karena adanya kesenjangan antara harapan dengan persepsi penumpang terhadap pelayanan kereta api. Dari analisis data yang dilakukan diperoleh hasil bahwa penumpang kereta api gerbong khusus wanita secara umum merasa tidak puas terhadap pelayanan yang diberikan oleh pengelola kereta api. Nilai kesenjangan antara harapan dan persepsi (gap) sebesar $-1,101$. Nilai tersebut merupakan gap 5 yakni kesenjangan antara expected service dengan perceived service.

Nilai kesenjangan yang negatif memiliki arti bahwa harapan yang dimiliki oleh penumpang lebih tinggi dibandingan persepsi yang dimilikinya. Walaupun diketahui bahwa harapan penumpang yang lebih tinggi, namun faktor yang paling berpengaruh terhadap harapan penumpang tersebut tidak diketahui pasti. Contohnya antara pengalaman pribadi atau kebutuhan pribadi yang paling berpengaruh terhadap harapan penumpang perlu dilakukan penelitian lebih lanjut. Sedangkan untuk persepsi terhadap pelayanan yang diterima penumpang (perceived service) dipengaruhi oleh penyajian pelayanan dan komunikasi dari pihak pengelola kereta api terhadap penumpang. Hal ini bisa disebabkan kesalahan penyajian pelayanan yang bermula dari kesalahan persepsi manajemen dan spesifikasi kualitas pelayanan atau terjadi kesalahan komunikasi namun untuk mengetahui seberapa besar kesalahan tersebut perlu penelitian lebih lanjut. 
Ketidakpuasan yang dirasakan oleh penumpang berkaitan dengan dimensi koneksi, reliabilitas, daya tanggap, dan bukti fisik. Yang paling dirasakan tidak memuaskan adalah dimensi koneksi. Yang termasuk ke dalam dimensi koneksi yaitu ketersediaan lapangan parkir, kemudahan akses ke stasiun dan frekuensi kereta api. Dari ketiga hal tersebut yang perlu diperhatian dari pihak pengelola kereta api adalah frekuensi kereta api. Saat ini, kereta api tidak selalu tersedia di stasiun, terkadang penumpang harus menunggu datangnya kereta api dari dipo ataupun stasiun lain. Hal ini dikarenakan jumlah kereta api yang lebih sedikit dari yang seharusnya dimiliki oleh pengelola kereta api.Jumlah kereta api yang dibutuhkan 500 unit sedangkan jumlah kereta api yang saat ini beroperasi hanya 386 unit (Johanita dalam Rakyat Merdeka ,2010). Kurangnya frekuensi kereta api disebabkan karena gangguan sinyal listrik yang sering terjadi. Seperti yang terjadi pada tanggal 7 januari 2011, terjadi gangguan sinyal listrik akibat kebakaran yang terjadi di Stasiun Jayakarta (Nurrachman, 2011).

Selain dimensi koneksi, dimensi reliabilitas, daya tanggap dan bukti fisik juga dirasakan kurang memuaskan bagi penumpang. Untuk dimensi reliabilitas yang menjadi sumber ketidakpuasan adalah pengelola kereta api yang tidak tepat waktu, contohnya: tidak tepat waktu memenuhi janji untuk membenahi pelayanan dan kereta api yang sering mengalami keterlambatan (Tabel 4..Nilai Kesenjangan antara Persepsi dan Harapan (SERVQUAL) per Dimesi). Sedangkan dalam dimensi daya tanggap yang menjadi sumber ketidakpuasan penumpang adalah kurangnya pemberian informasi yang jelas, benar dan tepat dari petugas kereta api baik di stasiun maupun di dalam gerbong kepada penumpang mengenai jadwal pemberangkatan, perubahan maupun masalah yang terkait dengan perjalanan kereta api. Yang terakhir dimensi yang dirasakan tidak puas adalah dimensi bukti fisik. Hal ini bisa terlihat kereta api yang selama ini beroperasi bukan kereta baru melainkan kereta bekas pakai negara Jepang yang diperbaiki oleh pengelola kereta api.

\section{PENUTUP}

Berdasarkan hasil analisis dan pembahasan dapat disimpulkan bahwa kepuasan penumpang kereta api terhadap layanan gerbong khusus kereta api wanita masih berada di level tidak puas. Terdapat kesenjangan antara nilai harapan dengan persepsi penumpang terhadap pelayanan kereta api gerbong khusus wanita yaitu sebesar $-1,101$. Unsur pelayanan yang dirasa tidak memuaskan bagi para penumpang yakni terkait dengan dimensi bukti fisik, reliabilitas, daya tanggap, dan koneksi. Oleh karena itu, perlu ada tindakan cepat dan nyata dari pengelola kereta api untuk memperbaiki keempat dimensi yang dirasa tidak puas oleh penumpang

\section{Saran}

Untuk pengelola kereta api disarankan: (a) Pengelola kereta api segera mengadakan perbaikan pelayanan pada unsur yang belum memenuhi harapan dari penumpang yaitu dimensi bukti fisik, reliabilitas, daya tanggap, dan koneksi; (b) Selain mengadakan perbaikan, pihak kereta api juga harus bisa mempertahankan layanan dari dimensi yang dirasakan penumpang sudah memenuhi kebutuhan atau harapannya walaupun belum maksimal. Sehingga di kemudian hari, level kepuasan penumpang akan meningkat. Sehingga kereta api menjadi moda transportasi yang terpecaya.

\section{DAFTAR PUSTAKA}

Arikunto,S.(2000). Manajemen Penelitian.Jakarta: Rineka Cipta

Hidajat, L.J. (2007).Panduan Penyusunan dan Penulisan Skripsi. Jakarta: Fakultas Psikologi Unika Atma Jaya 
Muryani. (2009). Kualitas Pelayanan Rumah Tahanan Negara Kelas 1 Jakarta Pusat menurut Persepsi Tahanan dan Narapidana. (Tugas akhir tidak dipublikasikan) Program Sarjana Jurusan Ilmu Sosial dan Ilmu Politik Universitas Indonesia

Nurdiyanto,D.F.(2008).Usaha Peningkatan Kualitas Pelayanan dengan Pendekatan Fuzzy dan Metode Service Quality pada Pusat Perbelanjaan Assalam Hypermarket.(Tugas akhir dipublikasikan). Program Sarjana Fakultas Teknik Universitas Muhamadiah Surakarta diambil dari

Sugiyono.(2010).Statistika untuk Penelitian. Bandung: Alfabeta.

Sunarto,R.S. (2009). Contractual Governance of Indonesia Railway System Case Study: Costumer Satisfaction in Jabodetabek Area vx Varmlandstrafik AB.(Tugas akhir tidak dipublikasi).Service Science Program Karlstad University

Supriyatmini, T.(2005). Pengaruh Persepsi Nasabah tentang Kualitas Pelayanan terhadap Loyalitas Nasabah pada Baitul Maal Wattamwil (BMT) “Anda” Semarang. Tugas akhir dipublikasikan. Program Sarjana Fakultas Ilmu Sosial Universitas Negeri Semarang diambil dari http:// digilib.unnes.ac.id/gsdl/ collect/skripsi/archives/ HASH01d0/ bdfcc341.dir/ doc.pdf

Susetyo,H. (2010). Transportasi Khusus Perempuan. Diambil dari http:// www. Indolawcenter.com/index.php?option $=$ com content\&view\&id=171:transportasi-khususperempuan\&catid $=52$ :artikel\&Itemid $=170$ pada 16 September 2010

Tjiptono,F., \& Chandra, G. (2007). Service, Quality \& Satisfaction. $2^{\text {nd }}$ ed. Yogyakarta: ANDI

Zeithaml,V.A.,Parasuraman, A.,\& Berry,L.L.(1990). Delivering Quality Service: balancing customer perception and expectation.New York: The Free Press 